\title{
PRODUÇÃO DA MANTA DE CONTENÇÃO A PARTIR DE FIBRA DE COCO VERDE
}

\section{Richard Antony Barbosa França ${ }^{1}$ \\ George Ribeiro Souza ${ }^{2}$ \\ Valdirene Aparecida da Silva ${ }^{3}$ \\ Erika Peterson Gonçalves ${ }^{4}$}

Resumo: O uso de manta de contenção é um importante produto que auxilia na resistência de um solo evitando assim o desmoronamento de terra ou problemas com compactação de solo, ou até auxiliando na drenagem do solo. Alternativas vêm sendo testadas nesse meio, e aliado a crescente necessidade de produção de materiais sustentáveis, foi desenvolvida uma manta com fibras de coco verde, produto que é encontrado em grande quantidade no território brasileiro que ao se consumir o fruto, as cascas são descartadas no lixo. O objetivo desse trabalho é a confecção dessa manta, para que se possa usar em reforço ao solo e a sua comparação com a manta de poliéster, vendida no mercado atual, através de testes mecânicos.

Palavras-chave: Fibra de coco; Manta; Solo; Resistência; Sustentabilidade.

\footnotetext{
1 Engenharia/Universidade do Vale do Paraíba, Brasil. E-mail: richardabf@hotmail.com.

2 Engenharia/Universidade do Vale do Paraíba, Brasil. E-mail: george_rse@hotmail.com.

3 Engenharia/Universidade do Vale do Paraíba, Brasil. E-mail: valdirene@univap.br.

4 Engenharia/Universidade do Vale do Paraíba, Brasil. E-mail: erika@univap.br.
} 